\title{
PENGATUR POTENSIO GANDA BERJANGKAH UNTUK MODUL PEMBELAJARAN PENGOPERASIAN MOTOR AC TIGA FASA
}

\author{
Wulan Ramadani ${ }^{1}$, Sunomo ${ }^{2}$ \\ ${ }^{1,2}$ Jurusan Pendidikan Teknik Elektro FT UNY \\ Email: wulanramadani1995@gmail.com
}

\begin{abstract}
This research was conducted to be able to set voltage and frequency of three phase voltage source with range $0-13 \mathrm{~V}$ to supply motor of three phase motor in power electronics practice. The use of low voltage aims to secure the measuring instrument or student from the possibility of a dangerous error. Methods carried out by taking steps, namely design, needs analysis, identification tools and materials, manufacture of hardware and software tools and testing. The designed system consists of four parts: (1) power supply, (2) minimum system, (3) motor driver strand, (4) program. Based on the test results obtained voltage range 0-13 volts, and frequency 0 $31.25 \mathrm{~Hz}$ in four positions ie stop, low speed, medium speed and high speed. The voltage and frequency regulator signal is obtained by changing the resistor value on two HEF4047 oscillators which controls the 3phase PWM IC HEF4752VP to produce the effect of simultaneous changes in voltage and frequency.
\end{abstract}

Keywords: Microcontroller, Three-phase Motor, Speed Control.

\begin{abstract}
ABSTRAK
Penelitian ini dilakukan untuk dapat mengatur tegangan dan frekuensi sumber tegangan tiga fasa dengan rentang $0-13 \mathrm{~V}$ untuk mencatu motor motor tiga fasa dalam praktik elektronika daya. Penggunaan tegangan rendah bertujuan mengamankan alat ukur maupun praktikan dari kemungkinan terjadi kesalahan yang membahayakan. Metode yang dilakukan dengan menempuh tahapan, yakni perancangan, analisa kebutuhan, identifikasi alat dan bahan, pembuatan perangkat keras dan perangkat lunak serta pengujian alat. Sistem yang dirancang terdiri dari empat bagian: (1) catu daya, (2) sistem minimum, (3) untai driver motor, (4) program. Berdasarkan hasil pengujian diperoleh rentang tegangan 0 - 13 volt, dan frekuensi $0-31,25 \mathrm{~Hz}$ dalam empat posisi yakni stop, kecepatan rendah, kecepatan sedang dan kecepatan tinggi. Sinyal pengatur tegangan dan frekuensi diperoleh dengan mengubah nilai resistor pada dua buah osilator HEF4047 yang mengendalikan IC PWM 3 fasa HEF4752VP untuk menghasilkan efek perubahan tegangan dan frekuensi secara serentak.
\end{abstract}

Kata kunci: Mikrokontroler, Motor Tiga Fasa, Pengatur Kecepatan.

\section{PENDAHULUAN}

Pengaturan kecepatan motor tiga fasa di industri sudah lazim digunakan sebagai pengganti pengaturan kecepatan motor arus searah yang boros perawatan. Menurut Martin Brown dalam Siemens Standard Drives Application Handbook (1997) maupun Hutt, Volrath dan Care, merawat motor arus bolakbalik lebih mudah dan lebih murah daripada merawat motor arus searah karena motor arus bolak-balik tidak membutuhkan sikat atau borstel sebagai penghubung aliran listrik ke bagian yang bergerak atau rotornya. Sikat ini merupakan masalah besar bagi motor karena bunga api listrik yang ditimbulkanya akibat gesekan maupun hubung singkat antar cabang lilitan rotornya ketika rotor berputar. Dampaknya, pada periode tertentu, sikat arang harus diganti. Sementara itu, perawatan pada motor arus bolak-balik hanyalah pada masalah pelumasan saja.

Dengan pertimbangan inilah para ahli berpikir untuk merancang sumber listrik yang dapat diatur frekuensinya untuk mengatur kecepatan motor bolak-balik. Motor arus bolak- 
balik yang digunakan sebagai penggerak, umumnya tiga fasa karena medan putarnya otomatis tidak perlu diciptakan di motornya, melainkan dari sumber listriknya sehingga pada daya yang motor yang sama, ukuran fisik motor arus bolak-balik tiga fasa menjadi lebih kecil daripada motor arus bolak-balik-balik satu fasa.

Karena kecepatan motor arus bolak-balik bergantung pada jumlah kutub dan frekuensi, jadi secara praktis jika kutubnya tetap, yang diatur adalah frekuensinya. Jika frekuensi motor turun, putaran motor juga akan turun, demikian juga sebaliknya. Masalahnya, untuk mempertahankan kekuatan putar (torsi motor), tidak hanya frekuensi yang diatur tetap juga tegangannya, sehingga muncul teori pengaturan motor tiga fasa yakni: VOLT/HERTZ dijaga konstan untuk menghasilkan torsi konstan. Pada frekuensi yang rendah, rugi tegangan pada resistansi stator perlu dikompensasi.

Pengaturan kecepatan motor tiga fasa pada tegangan masukan 45 volt per fasa melalui perbandingan volt/hertz sudah dibuat modulnya oleh Chandra Murti Agustina (2013), Nanda Christy (2013) dan Nurrohman (2014), sayangnya ketiganya masih menggunakan dua potensio pengatur terpisah, masing-masing untuk mengatur nilai tegangan dan nilai frekuensinya, sehingga tidak praktis karena harus memutar kedua potensio secara bersamaan agar perbandingan volt/herzt tetap konstan. Disisi lain dengan adanya perkembangan teknologi pengaturan kecepatan putaran motor dapat dilakukan secara otomatis dengan bantuan suatu sistem mikrokontroler. Penggunaan mikrokontroler dimaksudkan untuk memberikan kemudahan-kemudahan dalam penggunaannya. Dengan menggunakan mikrokontroler pengendalian kecepatan dapat dilakukan hanya dengan cara menekan tombol yang ada pada sistem tersebut.

Melalui penelitian ini, pengaturan kedua variable tersebut dilakukan secara otomatis tanpa gerakan mekanik, dan sifatnya berjangkah dengan bantuan mikrokontroler untuk mengatur besar tegangan dan frekuensi motor. Dalam penelitian ini pengaturan kecepatan motor dibatasi pada empat kecepatan motor yaitu dalam keadaan berhenti, berputar lambat, berputar dengan kecepatan sedang dan berputar dengan kecepatan tinggi.

\section{METODE}

Pemecahan masalah yang dilakukan dalam penelitian ini adalah dengan membuat pengatur tegangan dan frekuensi secara serentak dengan cara menekan tombol mekanik. Adapun diagram blok kerja alat yang akan dibuat dalam penelitian ini dijelaskan pada Gambar 1.

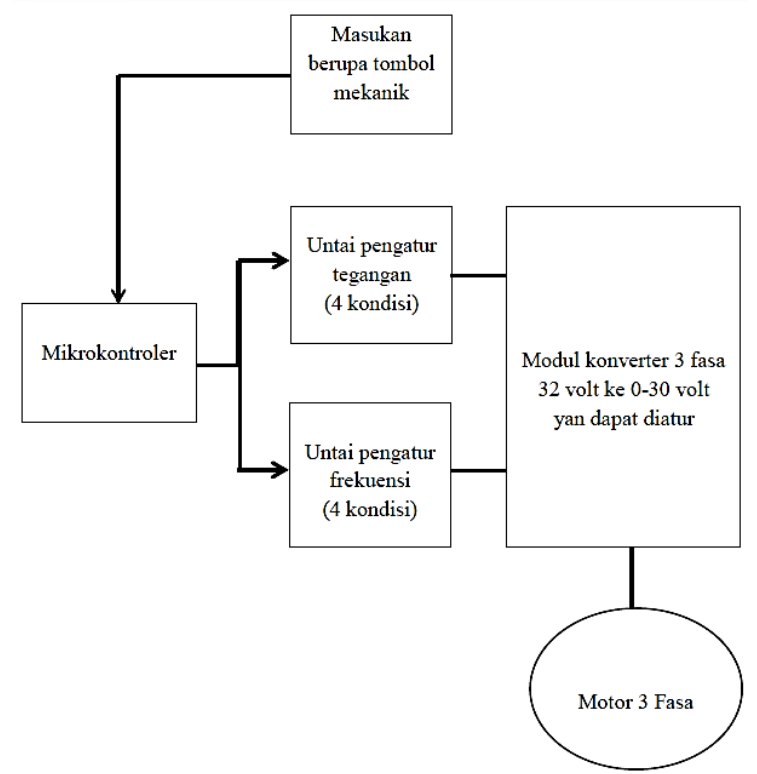

Gambar 1. Blok diagram kerja alat

Dari gambar diagram blok secara keseluruhan yang disajikan dalam gambar 2, dapat dijelaskan secara singkat prinsip kerja dari sistem pengaturan kecepatan putaran motor arus bolak-balik tiga fasa berbasis mikrokotroler ATMega 8535 ini, sehingga mengakibatkan terkendalinya putaran motor arus bolak-balik fasa tersebut.

Adapun cara kerja dari sistem tersebut diuraikan secara singkat sebagai berikut; 1) Tombol tekan (Push Button) digunakan sebagai input untuk memerintahkan mikrokontroler untuk melakukan perintah, 2) ATmega 8535 menerjemahkan perintah dari tombol tekan, 3) LCD sebagai penampil perintah dari tombol tekan yang telah diproses didalam 
mikrokontroler, 4) Rangkaian driver motor berfungsi menerjemahkan perintah yang dikeluarkan oleh sistem mikrokontroller sebagai pengatur kecepatan putaran motor.

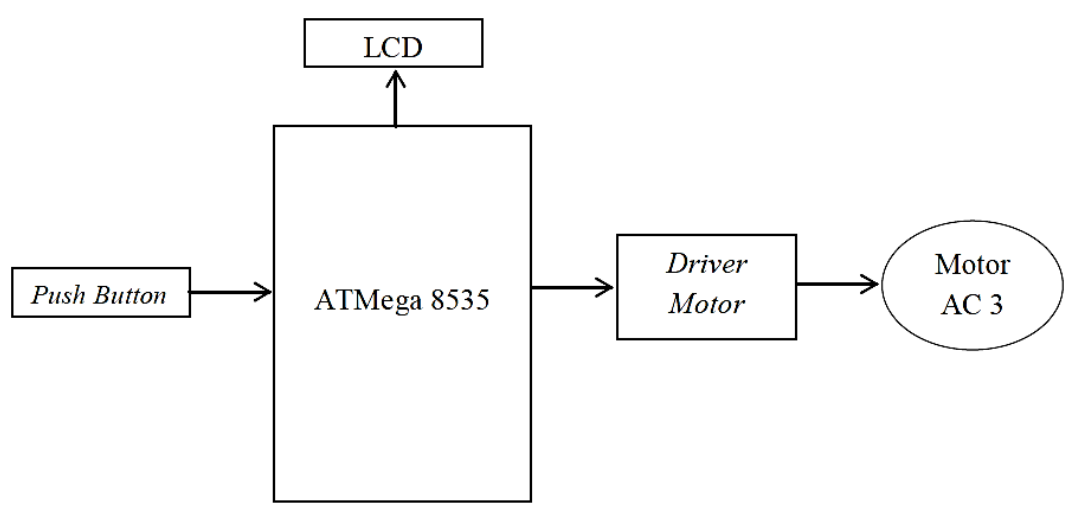

Gambar 2. Diagram Blok Rangkaian

Perancangan alat ini dimulai dari perancangan rangkaian catu daya, sistem minimum ATMega 8535 dan driver motor. Catu daya merupakan peranti yang paling penting dalam rangkaian elektronika, karena suatu rangkaian elektronika tidak akan bekerja jika tidak ada catu tegangan searah. Pada

perancangan alat ini daya yang digunakan adalah sebesar $5 \mathrm{~V}$ searah, daya tersebut digunakan untuk catu daya mikrokontroler. Karena mikrokontroler ATMega 8535 dapat bekerja jika diberi catu daya $5 \mathrm{~V}$ tegangan searah, rangkaian catu daya dapat dilihat pada Gambar 3.

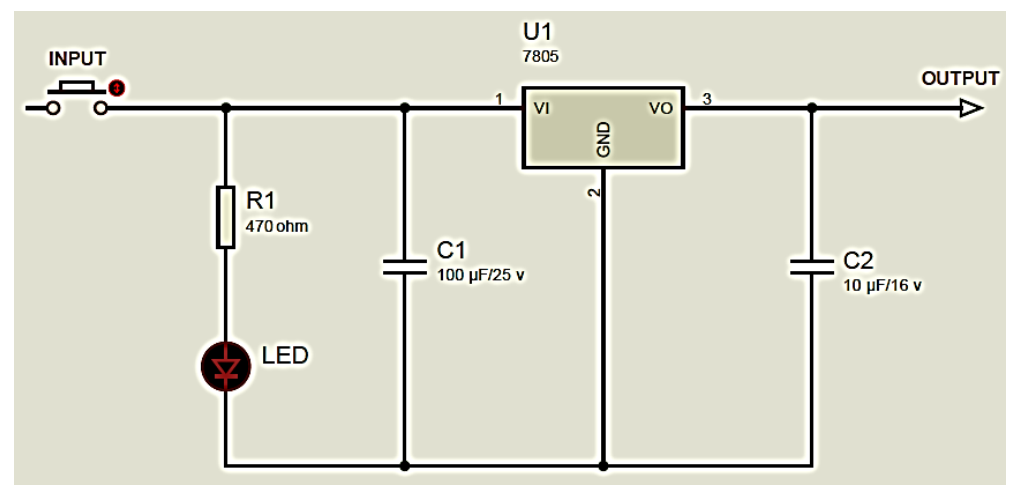

Gambar 3 .Rangkaian Catu Daya

Sistem minimum merupakan sistem yang terdiri dari komponen-komponen yang minimum sebagai pendukung kerja dari mikrokontroler agar dapat menjalankan perintah sesuai dengan apa yang kita inginkan. Pada perancangan alat ini terdapat 17 masukan dan keluaran yang digunakan yaitu : 1) PORT A digunakan sebagai keluaran sinyal Motor AC, 2) PORT B digunakan sebagai masukan tombol tekan sekaligus digunakan untuk mendownload program dari CodeVision AVR, 3) PORT D digunakan sebagai keluaran LCD untuk menampilkan perintah dari tombol tekan. 


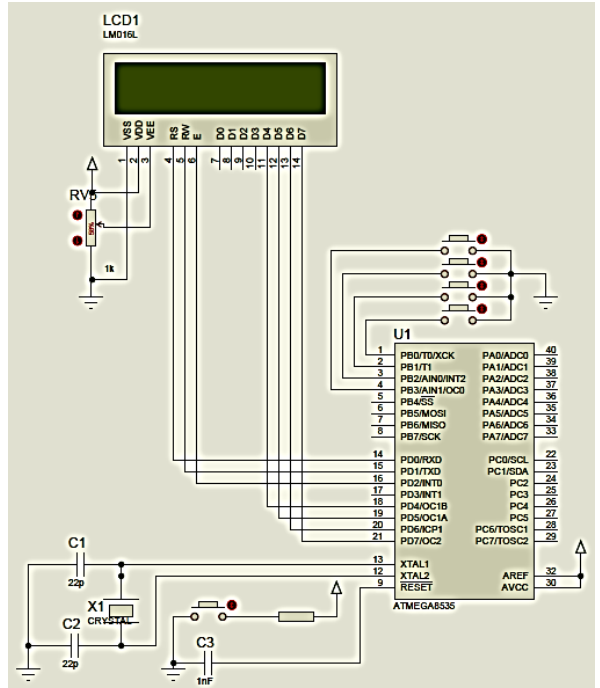

Gambar 4. Rangkaian Sistem Minimum ATmega 8535

Ranglaian driver motor berfungsi untuk membantu memperkuat sinyal keluaran mikrokontroler agar mampu mengontrol motor. Rangkaian bekerja dengan membalik sinyal keluaran dari mikrokontroler sehingga motor dapat dikendalikan. Rangkaian ini terdiri dari Transistror NPN yang dirangkai agar dapat membalik sinyal keluaran dari mikrokontroler, kemudian sinyal tersebut masuk ke IC 4067 yang kemudian digunakan sebagai driver motor arus bolakbalik tiga fasa. Adapun rangkaian driver motor yang dirancang adalah sebagai berikut :

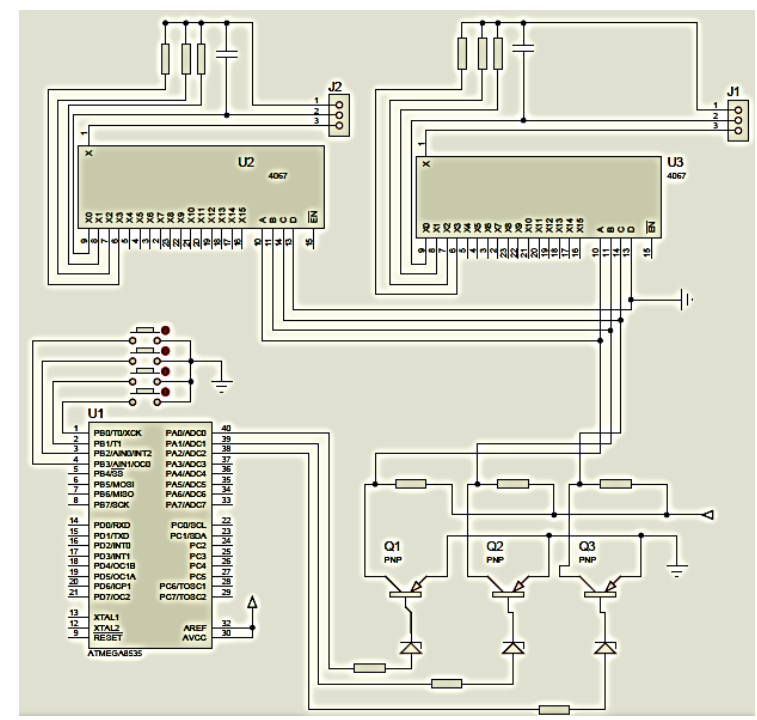

Gambar 5. Driver Motor

Perancangan bahasa program digunakan untuk menjalankan sebuah mikrokontroler agar mikrokontroler tersebut bisa bekerja sesuai dengan yang diinginkan. Pemrograman mikrokontroler ATMega 8535 dilakukan dengan menggunakan bahasa C. Perancangan bahasa program sangatlah penting karena merancang secara keseluruhan program yang akan dibuat dan dijalankan. Perancangan bahasa program ini menggunakan perangkat lunak CodeVision AVR, suatu perangkat lunak program C Compiler berbasis Windows untuk mikrokontroler keluarga AVR seperti ATmega, ATtiny, AT90xx dan AT86xx. CodeVision AVR merupakan perangkat lunak untuk pembuatan program dengan menggunakan bahasa C. Sebelum diunduh ke dalam IC mikrokontroler, bahasa $\mathrm{C}$ tersebut di-compile terlebih dahulu ke dalam format (Hex.), kemudian baru file dengan fomat hex tersebut diunduh dengan perangkat pengunduh (Downloader).

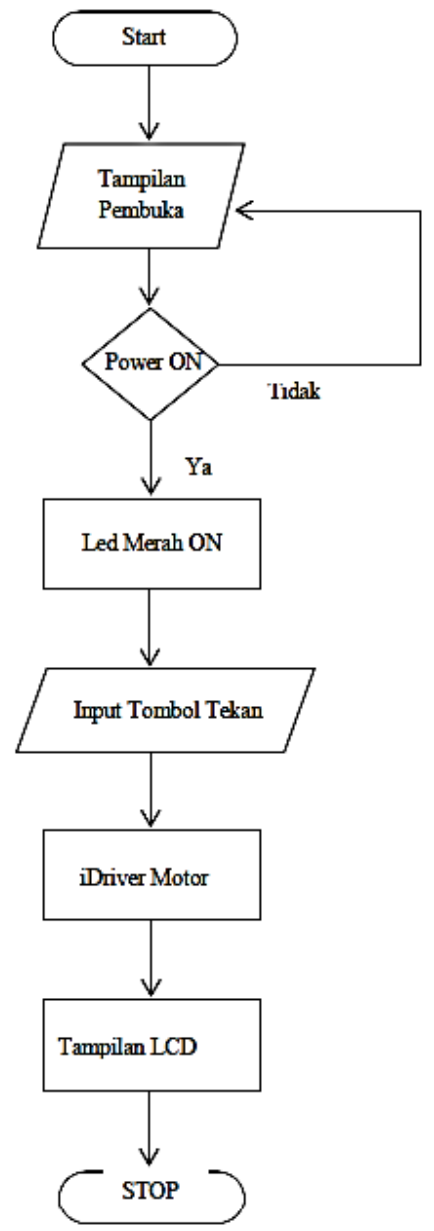

Gambar 6. Flowchart

Pengujian merupakan proses yang digunakan untuk mengetahui apakah alat 
bekerja atau tidak. Pengujian yang dilakukan meliputi Uji Fungsional dan Uji Unjuk Kerja. Uji Fungsional dilakukan dengan cara menguji setiap bagian alat berdasarkan karakteristik dan fungsi masing-masing. Pengujian ini dilakukan untuk mengetahui apakah setiap bagian dari perangkat telah bekerja sesuai dengan fungsi dan keinginan. Uji Unjuk Kerja dilakukan dengan cara melihat unjuk kerja alat. Hal-hal yang perlu diamati antara lain: rangkaian sistem minimum, rangkaian dan rangkaian driver motor. Dari pengujian ini akan diketahui kinerja dari alat yang dibuat.

\section{HASIL DAN PEMBAHASAN}

Pengujian dilakukan untuk mengetahui unjuk kerja alat yaitu apakah alat dapat bekerja atau tidak dalam mengatur kecepatan motor tiga fasa bolak-balik dengan menggunakan tombol mekanik dan memanfaatkan perubahan frekuensi dan tegangan. Pengujian dilakukan di Laboratorium Elektronika Daya Jurusan Pendidikan Teknik Elektro Universitas Negeri Yogyakarta.

Hasil pengujian dan pengukuran pertama yaitu pada keluaran catu daya menggunakan multimeter. Hasil pengukurannya dapat dilihat pada Tabel dibawah ini:

Tabel 1. Hasil pengukuran regulator tegangan LM7805

\begin{tabular}{c|l|l|l}
\hline No. & Pengukuran & $\begin{array}{c}\text { Tegangan } \\
\text { Masukan } \\
(\text { volt })\end{array}$ & $\begin{array}{c}\text { Tegangan } \\
\text { Keluaran } \\
\text { (volt) }\end{array}$ \\
\hline 1. & Tanpa Beban & 12 & 5 \\
\hline 2. & Dengan Beban & 12 & 5 \\
\hline
\end{tabular}

Hasil pengujian logika keluaran mikrkontroler dapat dilihat pada Tabel 2 dibawah ini.

Tabel 2. Logika pada mikrokontroler

\begin{tabular}{c|c|c|c|c|c|c|c}
\hline \multirow{2}{*}{ No } & \multicolumn{4}{|c|}{ Masukan } & \multicolumn{3}{c}{ Keluaran } \\
\cline { 2 - 8 } & PB0 & PB1 & PB2 & PB3 & PA0 & PA1 & PA2 \\
\hline 1 & 0 & 1 & 1 & 1 & 0 & 0 & 0 \\
\hline 2 & 1 & 0 & 1 & 1 & 1 & 0 & 0 \\
\hline 3 & 1 & 1 & 0 & 1 & 0 & 1 & 0 \\
\hline 4 & 1 & 1 & 1 & 0 & 1 & 1 & 0 \\
\hline
\end{tabular}

Tabel 3 .Pengujian LCD

\begin{tabular}{c|c|c|c|c|c}
\hline \multirow{2}{*}{ No } & \multicolumn{4}{|c|}{ Masukan } & \multirow{2}{*}{ Tampilan LCD } \\
\cline { 2 - 5 } & PB0 & PB1 & PB2 & PB3 & \\
\hline 1 & 0 & 1 & 1 & 1 & STOP \\
\hline 2 & 1 & 0 & 1 & 1 & LOW SPEED \\
\hline 3 & 1 & 1 & 0 & 1 & MEDIUM SPEED \\
\hline 4 & 1 & 1 & 1 & 0 & HIGH SPEED \\
\hline
\end{tabular}

Pengujian logika pada untai kendali motor dilakukan dengan mengecek logika pada IC 4067, logika pada IC 4067 dikendalikan dari keluaran mikrokontroler, tetapi logikanya berkebalikan dengan logika keluaran dari mikrokontroler. Hal ini disebabkan adanya untai transistor common emitter sebagai saklar yang rangkai pada keluaran mikrokontroler hal ini dilakukan karena IC 4067 membutuhkan tegangan masukan sebesar 12 volt sedangkan tegangan keluaran dari mikrokontroler hanya sebesar 5 volt, sesuai dengan karakteristik dari transistor common emitter yaitu sinyal berbalik fasa 180 derajat terhadap sinyal masukan, jadi apabila sinyal dari mikrokontroler logika 0 maka sinyal keluaran pada transistor adalah 1 , sinyal keluaran transistor tersebut menjadi sinyal masukan pada IC 4067.

Tabel 4. Hasil pengujian logika pada IC 4067

\begin{tabular}{c|c|c|c|c|c|c|c}
\hline \multirow{2}{*}{ No } & \multicolumn{2}{|c|}{$\begin{array}{l}\text { Logika Keluaran } \\
\text { Mikrokontroler }\end{array}$} & \multicolumn{5}{|c}{ Logika Pada IC 4067 } \\
\cline { 2 - 8 } & PA0 & PA1 & PA2 & A & B & C & D \\
\hline 1 & 0 & 0 & 0 & 1 & 1 & 1 & 0 \\
\hline 2 & 1 & 0 & 0 & 0 & 1 & 1 & 0 \\
\hline 3 & 0 & 1 & 0 & 1 & 0 & 1 & 0 \\
\hline 4 & 1 & 1 & 0 & 0 & 0 & 1 & 0 \\
\hline
\end{tabular}

Tabel 5. Hasil saklar pada IC 4067

\begin{tabular}{c|c|c|c|c|c}
\hline \multirow{2}{*}{ No } & \multicolumn{4}{|c|}{ Logika Pada IC 4067} & \multirow{2}{*}{$\begin{array}{c}\text { Kaki yang aktif } \\
\text { pada IC 4067 }\end{array}$} \\
\cline { 2 - 5 } & A & B & C & D & 2 \\
\hline 1 & 1 & 1 & 1 & 0 & 3 \\
\hline 2 & 0 & 1 & 1 & 0 & 4 \\
\hline 3 & 1 & 0 & 1 & 0 & 5 \\
\hline 4 & 0 & 0 & 1 & 0 & \\
\hline
\end{tabular}

Pada pengujian gelombang frekuensi pengamatan dilakukan menggunakan osiloskop. Osiloskop yang digunakakan adalah osiloskop digital tiga fasa berfasilitas empat kanal sehingga bentuk gelombang dapat terlihat lebih jelas. Pengamatan ini bertujuan untuk 
mengetahui lebar pulsa masukan IC HEF4752VP pada setiap posisi putaran motor. Pengamatan dilakukan pada kaki 12 (FCT), 4(RCT), 17 (VCT), dan 6 (OCT). Posisi probe osiloskop kanal 1 pada kaki FCT, posisi probe osiloskop kanal 2 pada kaki RCT, posisi probe osiloskop kanal 3 pada kaki VCT, dan posisi probe osiloskop kanal 4 pada kaki OCT. Hasil pengamatan dapat dilihat dari gambar dibawah ini.
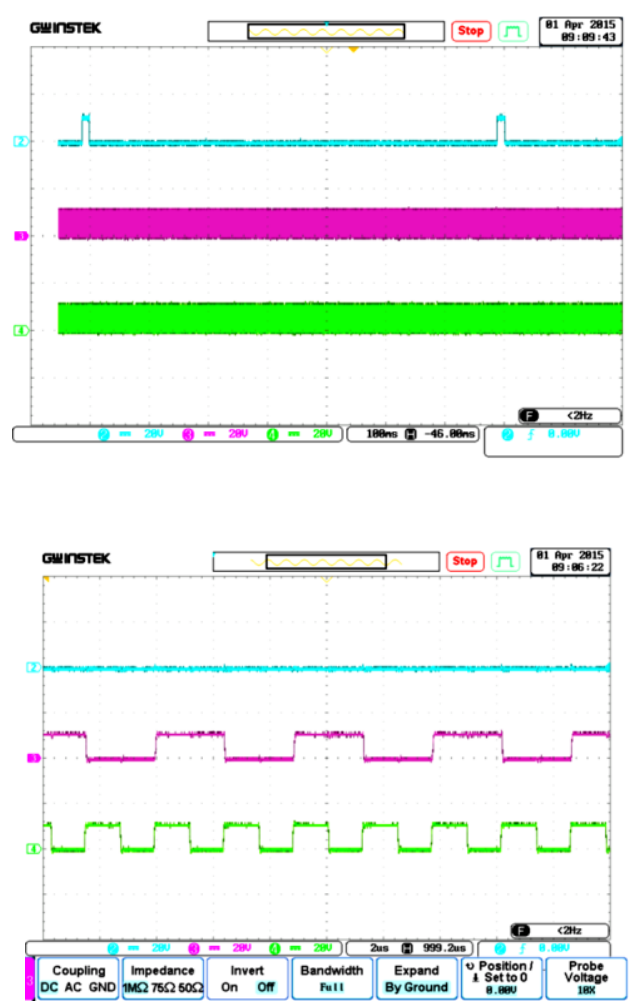

Gambar 7. Frekuensi Masukan IC HEF4752VP Pada Posisi Stop

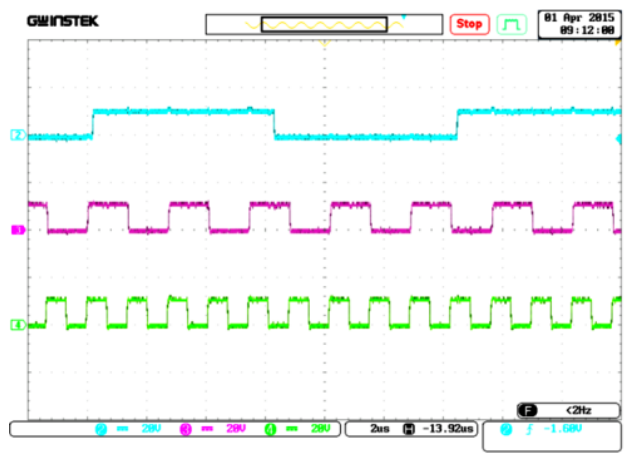

Gambar 8. Frekuensi Masukan IC HEF4752VP Pada Posisi Low

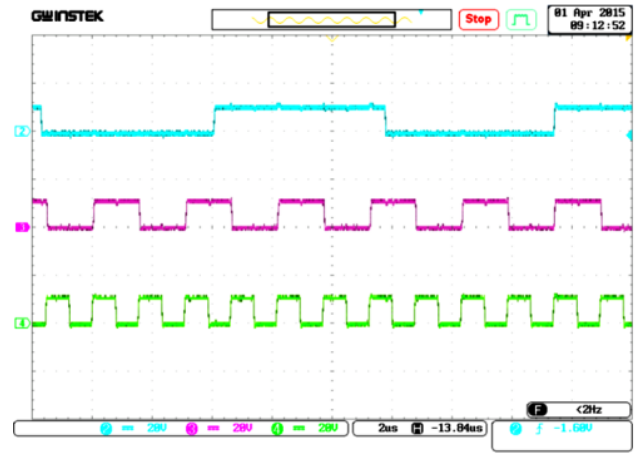

Gambar 9. Frekuensi Masukan IC HEF4752VP Pada Posisi Medium

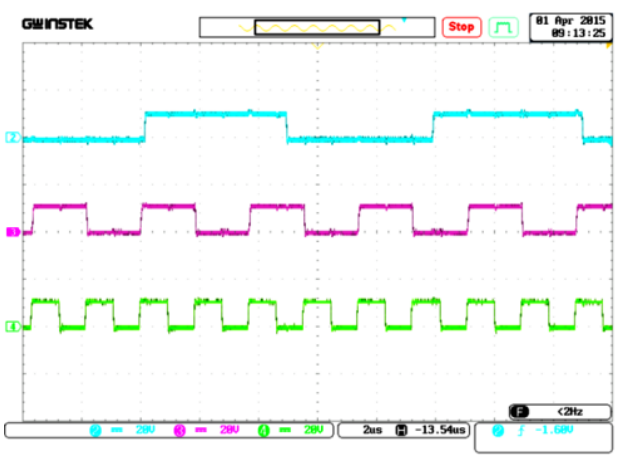

Gambar 10. Frekuensi Masukan IC HEF4752VP Pada Posisi High

Dari hasil pengukuran saat posisi motor berhenti (STOP), LOW, MEDIUM dan HIGH dapat dihitung tinggi tegangan keluaran dan lebar frekuensinya.

Tabel 6. Hasil Pengamatan Frekuensi Masukan IC HEF4752VP

\begin{tabular}{|c|c|c|c|c|}
\hline \multirow{2}{*}{$\begin{array}{c}\text { Posisi } \\
\text { Motor }\end{array}$} & $\begin{array}{c}\text { No. } \\
\text { Gambar }\end{array}$ & $\begin{array}{c}\text { Kanal 2 } \\
(\mathrm{kHz})\end{array}$ & $\begin{array}{c}\text { Kanal 3 } \\
(\mathrm{kHz})\end{array}$ & $\begin{array}{c}\text { Kanal 4 } \\
(\mathrm{kHz})\end{array}$ \\
\cline { 3 - 5 } & 27 & $1.42 \mathrm{~Hz}$ & 208.33 & 416.67 \\
\hline Stop & 28 & 81.967 & 357.14 & 806.45 \\
\hline Low & 29 & 87.719 & 312.5 & 625 \\
\hline Medium & 30 & 102.04 & 277.78 & 555.556 \\
\hline
\end{tabular}

Pengamatan gelombang frekuensi dan tegangan pada beban simulasi ballast 50W/220VAC sambungan bintang dilakukan dengan menggunakan osiloskop digital tiga fasa empat kanal. Pengamatan ini bertujuan untuk mengetahui lebar dan tinggi gelombang pada setiap pengaturan posisi putaran motor. Pengamatan dilakukan pada kaki fasa R,S dan 
T. Posisi probe osiloskop kanal 1 pada fasa $\mathrm{T}$, posisi probe osiloskop kanal 2 pada fasa $S$, posisi probe osiloskop kanal 3 pada fasa $\mathrm{R}$, dan posisi probe osiloskop kanal 4 pada sambungan bintang beban. Hasil pengamatan dapat dilihat dari gambar dibawah ini.

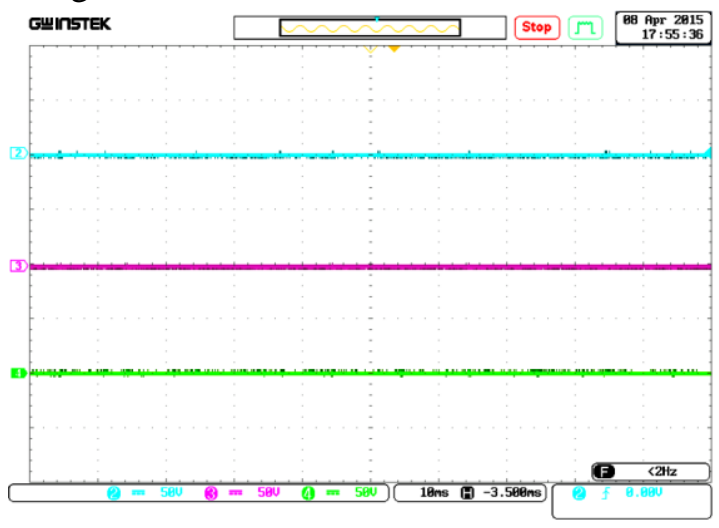

Gambar 11. Frekuensi Keluaran Beban Pada Posisi Stop

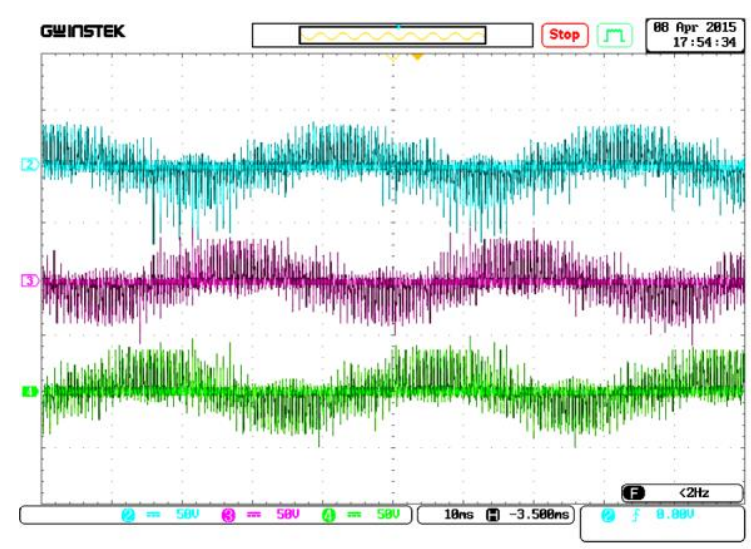

Gambar 12. Frekuensi Keluaran Beban Pada Posisi Low

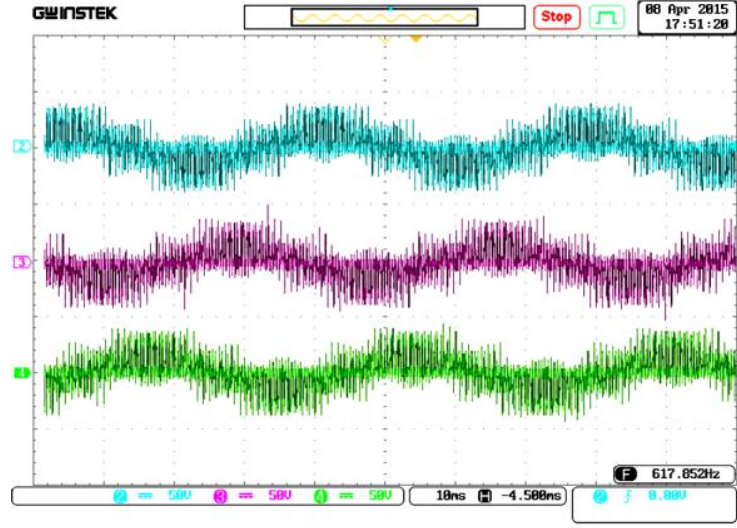

Gambar 13 . Frekuensi Keluaran Beban Pada Posisi Medium

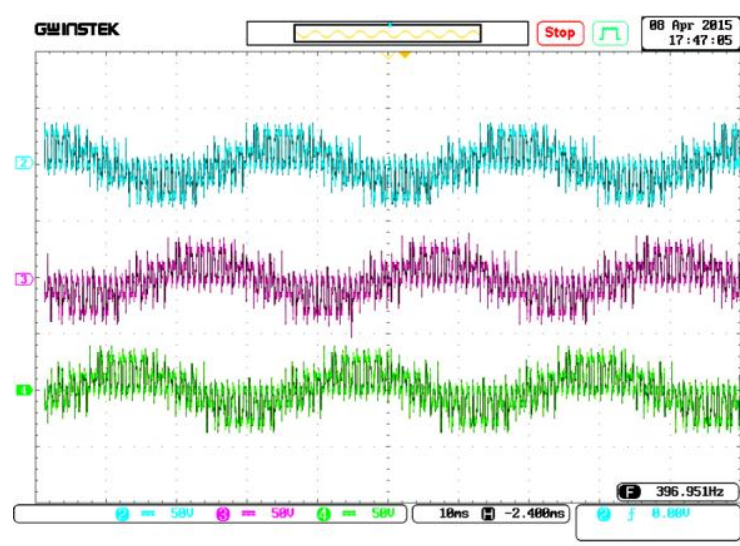

Gambar 14. Frekuensi Keluaran Beban Pada Posisi High

Tabel 7. Hasil Pengamatan Frekuensi Keluaran Beban

\begin{tabular}{|c|c|c|}
\hline Posisi Motor & No. Gambar & Frekuensi (Hz) \\
\hline Stop & 31 & 0 \\
\hline Low & 32 & 25 \\
\hline Medium & 33 & 26.315 \\
\hline High & 34 & 31,25 \\
\hline
\end{tabular}

Pengukuran tegangan keluaran IC HEF4752 dilakukan dengan osiloskop, multimeter analog dan multimeter digital, hasil pengukuran tegangan keluaran dapat dilihat pada Tabel 8. 
Tabel 8. Pengukuran Tegangan dan Frekuensi Keluaran IC HEF4752

\begin{tabular}{|c|c|c|c|c|c|}
\hline Posisi Motor & $\begin{array}{c}\text { Multimeter } \\
\text { Analog (Volt) }\end{array}$ & $\begin{array}{c}\text { Multimeter } \\
\text { Digital } \\
\text { (Volt) }\end{array}$ & $\begin{array}{c}\text { Osiloskop } \\
\text { (Vrms) }\end{array}$ & $\begin{array}{c}\text { Frekuensi } \\
\text { (Hz) }\end{array}$ & Volt/Hz \\
\hline Stop & 0 & 0 & 0 & 0 & - \\
\hline Low Speed & 12 & 8.09 & 7.07 & 25 & 0.32 \\
\hline $\begin{array}{c}\text { Medium } \\
\text { Speed }\end{array}$ & 10 & 10.49 & 10.6 & 26.315 & 0.38 \\
\hline \begin{tabular}{c} 
High Speed \\
\hline
\end{tabular} & 13 & 13 & 14.14 & 31.25 & 0.42 \\
\hline
\end{tabular}

Catatan : Vrms Osiloskop dihitung dari $\frac{V p p}{2 \sqrt{2}}$

Dari hasil pengamatan gelombang masukan IC HEF4752VP pada Tabel 6 dapat diketahui bahwa rentang nilai frekuensi pada kaki FCT $=1.42 \mathrm{~Hz}$ sampai $102.04 \mathrm{kHz}, \mathrm{VCT}=$ $208.33 \mathrm{kHz}$ sampai $357.14 \mathrm{kHz}$ dan OCT= $416.67 \mathrm{kHz}$ sampai $806.45 \mathrm{kHz}$. Besar nilai frekuensi dipengaruhi oleh besar kecilnya nilai resistor dan kapasitor penentu frekuensi pada IC HEF4047B. Semakin besar hambatan pada IC HEF4047B maka nilai frekuensi akan semakin kecil, sebaliknya jika nilai hambatan kecil maka nilai frekuensi semakin besar.

Dari hasil pengamatan pada Tabel 8 rentang nilai frekuensi pada beban bekisar antara 0 sampai $31.25 \mathrm{~Hz}$, sedangkan nilai tegangannya bekisar antara 0 sampai 13 Volt. Besar nilai frekuensi dan tegangan pada beban juga dipengaruhi oleh nilai resistor pada IC 4047. Semakin besar nilai resistor maka nilai frekuensi dan tegangan semakin kecil, begitu juga sebaliknya jika nilai resistor kecil maka nilai frekuensi dan tegangan semakin besar. Dari perbandingan volt/hertz dapat dilhat pada Tabel 8 perbandingannya relatif konstan.

\section{SIMPULAN}

Setelah melakukan uji coba alat yang dibuat dapat mengubah nilai tegangan dan frekuensi secara serentak pada empat posisi, yakni: stop, low, medium dan high. Rentang tegangan yang diperoleh adalah $0-13$ volt dan rentang frekuensi $0-31.25 \mathrm{~Hz}$.

Pengaturan nilai potensio ganda ini menggunakan mikrokontroler yang telah diprogram menggunakan perangkat lunak kemudian keluaran dari mikrokontroler inilah yang mengendalikan IC4067 dan dari keluaran IC4067 ini digunakan untuk mengendalikan IC4047 sebagai pembangkit frekuensi dan tegangan.

Besar nilai tegangan dan frekuensi dipengaruhi oleh besarnya hambatan pada IC pembangkit frekuensi dan pembangkit tegangan. Semakin besar nilai hambatan maka semakin kecil frekuensi dan tegangan yang dihasilkan. Sebaliknya jika hambatan semakin kecil maka nilai tegangan dan frekuensi semakin besar.

\section{DAFTAR RUJUKAN}

Amfa. 2011. Motor Induksi 3 Fasa. Diambil dari http://kuliahelektro.blogspot.com/ 2011/01/motor-induksi-3-fasa_30.html pada tanggal 10 Maret 2015.

Atmel Corporation. 2003. 8-bit Microcontroller with $8 K$ Bytes In-System Programmable Flash ATmega8535 ATmega8535L. Diambil dari : http://www.alldatasheet.com, pada tanggal 04 Januari 2015.

Badruzzaman, Yusnan. 2015. Pengereman Dinamik Pada Motor Induksi Tiga Fasa. Diambil dari https://www.academia.edu/ 8033690/PENGEREMAN_MOTOR_IND UKSI_TIGA_FASA, pada tanggal 10 Maret 2015.

Bayu Aji Nugroho. 2014. Mesin Induksi Tiga Fasa. Makalah. Sekolah Tinggi Teknik PLN Jakarta. 
Edi Permadi. 2005. Antarmuka LED. Diambil dari https://eepu.files.wordpress.com/ 2007/09/antarmuka-led.pdf diunduh pada tanggal 10 Maret 2015.

Freescale Semiconductor. 2005. 3-Phase AC Motor Control with $\mathrm{V} / \mathrm{Hz}$ Speed Closed Loop Using the 56F800/E. Diambil http://cache.freescale.com/files/dsp/doc/a pp_note/AN1958.pdf, pada 10 Maret 2015.

Haryanto, Heri. 2011. Pembuatan Modul Inverter sebagai Kendali Kecepatan Putaran Motor Induksi. Diambil dari http://lppm.trunojoyo.ac.id/upload/peneli tian/penerbitan_jurnal/02_REKAYASA

Nur Rohman Eko Nugroho. 2014. Konverter Tegangan dan Frekuensi Tiga Fasa Variabel dengan Rangkaian Kemudi IC
HEF4752VP. Proyek Akhir. Universitas Negeri Yogyakarta.

Philips Semiconductor. 1995. Datasheet IC HEF4752VP. Diambil dari http://pdf.datasheetcatalog.com/datashee t/philips/HEF4752VP.pdf , pada 10 Maret 2015.

Sunyoto. 1993. Mesin Arus Bolak-balik. Yogyakarata: IKIP Yogyakarta.

Texas Instrument. 2003. Datasheet IC CD4067B. Diambil dari http://www.ti.com/lit/ds/symlink/cd4067b. pdf, pada 04 Januari 2015.

Texas Instrument. 2003. $\mu A 7800$ SERIES POSITIVE-VOLTAGE REGULATORS. dari https://www.sparkfun.com/ datasheets/Components/LM7805.pdf, pada 04 Januari 2015. 